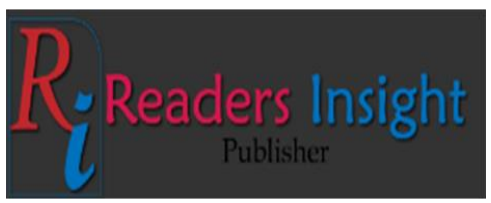

\author{
Pak-Euro Journal of Medical and Life Sciences \\ ISSN: 2707-4471 (Print), 2707-448X (Online) \\ www.readersinsight.net/pjim/s
}

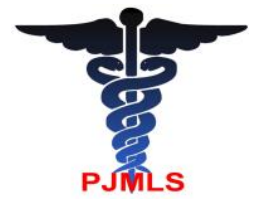

Research Article

\title{
Determination the Effects of Hyperthyroidism on Pre-Eclampsia in Women of Balochistan
}

\author{
Zarmina Khan Mandokhail ${ }^{1}$, Masroor Ahmad Bajwa*1, Talha Shahid Amin², Irfan Shahzad Sheikh", \\ Majed Rafeeq ${ }^{1}$, Muhammad Tauseef Asmat ${ }^{1}$, Shaista Nasir Khan ${ }^{1}$, Nazira Rashid ${ }^{1}$, Sakeena \\ Naeem $^{3}$, Khair un Nisa Najmi ${ }^{4}$, Mubshira Mandokhail ${ }^{5}$, Maira Ejaz ${ }^{6}$ and Shandana Khan \\ Mandokhail6.
}

${ }^{1}$ Center for Advanced Studies in Vaccinology and Biotechnology, University of Balochistan, Quetta, Pakistan.
${ }^{2}$ Akhtar Saeed Trust, Lahore, Pakistan.
${ }^{3}$ Gynea-unit-1Sandeman Provincial Hospital Quetta, Balochistan, Pakistan.
${ }^{4}$ Department of Gynaecology and Obstetrics,Jillani Hospital, Quetta, Balochistan, Pakistan.
${ }^{5}$ United Medical and Dental College Karachi, Sindh, Pakistan.
${ }^{6}$ Zoology and Biotecnology Department, Sardar Bahadur Khan Women University, Quetta,Balochistan, Pakistan.

${ }^{*}$ Corresponding author: bajwamasroor@yahoo.com

\begin{abstract}
Thyroid gland is an endocrine gland that reproduces hormones that regulates the body metabolic rate and other body functions. Hyperthyroidism is the dysfunction of thyroid gland which interferes during $2^{\text {nd }}$ and $3^{\text {rd }}$ trimester of pregnancies producing pre-eclamptic disorder in pregnant women. These disorders may cause deaths as well as morbidity losses in mothers and fetus. Hyperthyroidism is highly associated with the onset of pre-eclampsia. Pre-eclampsia is detected by elevated levels of proteinuria as well as systolic and diastolic blood pressures. The study focuses on the identification of factors associated with hyperthyroidism and preeclampsia and to create awareness regarding this important health issue during pregnancy which may lead to eclamptic seizures during onset of full term labor and are found to be fatal for women and neonate during pregnancy. This study was conceded to discover the influence of hyperthyroidism on pre-eclamptic women of Balochistan. For the purpose, one hundred one (101) pregnant women of 15-50 years of age were selected for this study to attain comprehensive history, physical and medical examination according to the inclusion and exclusion criteria. Patients of different ethnic groups were examined at Out Patient Department (OPD) in Centre for Nuclear Medicine and Radio therapy (CENAR), Sandeman Provincial Hospital and Bolan Medical Complex Hospital (BMC), Quetta.. The current study revealed that out of 101 hyperthyroid patients $61.4 \%$ and $20.8 \%$ patients belong to Pashtoon and Baloch ethnic groups respectively. It was also found that 44 out of 101 patients lie in age group of 26-35 years. It was observed that highly educated, strong socioeconomic women developed less Pre-eclampsia. Pre-eclampsia was found to be in a significant numbers (33), in hyperthyroid patients, with highest frequency of Pedal edema (36.6\%). It was concluded that hyperthyroidism in association with pre-eclampsia was effected by ethnicity, age,socioeconomic status, education level and the onset of edema.
\end{abstract}

Keywords:Pre-eclampsia, Hyperthyroidism, Edema, Age, Ethnicity

\section{ARTICLE INFORMATION}

Received: 12.07 .2019

Revised: 14.08 .2019

Accepted: 30.09 .2019

DOI: 10.31580/pjmls.v2i3.1128

\section{INTRODUCTION}

Thyroid gland is present at the 3rd tracheal ring situated at the anterior position of the trachea[6]. "Histologically" thyroid gland is comprised of follicles in which thyroid hormone is synthesized [40]. It releases two hormones named as Triiodothyronine (T3) and Thyroxin (T4). T3 and T4 hormones help to regulate metabolism are tyrosine based. Thyroid hormone has various functions ranging from increased sensitivity of the body to catecholamine, maturation of neurons, long bone growth, regulation of metabolic rate, synthesis of protein, proper development and differentiation of all human body cells. Inadequate hormone production may cause hypothyroidism while too much secretion results in a condition called as hyperthyroidism. Reports show evidences of primary hypothyroidism under the action of thyroid gland [4]. It may delay the growth and development of the baby during pregnancy causing iodine deficiency [40]. Hyperthyroidism can increase the rate of body's metabolism, sudden weight reduction, fast or uneven heartbeat, male and female reproductive disorders [27]. Hyperthyroidism is related with reduced fertility. Women with hyperthyroidism have $5-8 \%$ of infertility[11]. In some cases of 
endometrial biopsies showed the evidence of ovulation in women [10]. Over all $1-5 \%$ of conceptions are involved due to a medical disorder hypertension[20]. According to a survey of World Health Organization (WHO) in a period during 2003 to 2009 , pre-eclampsia is a hypertensive disorder causing $14.0 \%$ of maternal deaths[33]. Hypertension and pre-eclampsia were found during pregnancy that may leads to mother and fetus mortality. Pre-eclampsia is a pregnancy disorder which usually happens by an elevation in blood pressure (systolic/diastolic $\geq 140 / 90 \mathrm{mmHg}$ ) after 20 weeks, with proteinuria and edema. Pre-eclampsia is the secondary reason of maternal mortality in Indonesia, $7-10 \%$ from all maternal mortality that happened. Pre-eclampsia, a pregnancy syndrome is identified through proteinuria and hypertension [36]. Edema is the term used for swelling. Medications, pregnancy, infections, preeclampsia and many other medical problems can cause edema. Signs of pre-eclampsia comprises of hypertension, proteinuria with edema, rapid weight gain, headache, nausea, vomiting during the pregnancy [3]. Additionally, the symptom of eclampsia or extreme pre-eclampsia was increasing in women with the risk of severe obstetric losses [16].Pre-eclampsia had complicated 2.0 to $8.0 \%$ pregnancies worldwide [28] with variation across regions [1]. Pre-eclampsia in $50 \%$ of overall early conceptions is dangerous for the next pregnancy after the first one. Delivery is the only cure for clinical pre-eclampsia [29][18]. Pre-eclampsia affects 3 to $5 \%$ of pregnancies and is also associated with hypertension in 20 weeks' of pregnancies and fetus growth. In pre-eclampsia disorder in pregnant women and fetus are evident [30]. Other signs like edema, liver and renal dysfunction, Hemolysis Elevated Liver Enzymes Low Platelets Count (HELLP), affect the clinical condition [17].

Pre-eclampsia divides women patients having low to the higher risks factors. Pre-eclampsia, is a pregnancy disease causing certain problems in mother and fetus such as eclampsia, placenta abruption, kidney failure, blood related diseases, postpartum haemorrhage $(\mathrm{PPH})$, intrauterine growth retardation, pre mature birth, death of mother and fetus [15].Douglas and Redman, (1994) found that only $10 \%$ of pregnant women were in eclamptic seizure. Pre-eclampsia at early age of gestation, shows considerable maternal deaths under 32 weeks' of incubation [21].Pre-eclampsia can be monitored, diagnosed and predict which patients may develop the signs of this condition through awareness [12]. The scope and objectives of the study were to evaluate the incidence of hyperthyroidism inrelation with pre-eclamptic pregnant women of various ethnic and age groups of Balochistan province.

Table 1.Distribution of patients according to ethnic groups

\begin{tabular}{ccc}
\hline Ethnic groups & Number of patients & $\%$ of patients \\
\hline Pashtoon & 62 & 61.4 \\
Baloch & 21 & 20.8 \\
Punjabi & 10 & 9.9 \\
Others & 8 & 7.9 \\
Total & 101 & 100.0 \\
\hline
\end{tabular}

Table 2. Number of hyperthyroid patients in different age groups

\begin{tabular}{ccc}
\hline Age groups & Number of patients & $\%$ of patients \\
\hline $15-25$ & 26 & 25.7 \\
$26-35$ & 44 & 43.6 \\
$36-50$ & 31 & 30.7 \\
Total & 101 & 100.0 \\
\hline
\end{tabular}

Table 3. Socioeconomic status of hyperthyroid patients

\begin{tabular}{cccc}
\hline Groups & $\begin{array}{c}\text { Percentage of } \\
\text { patients }\end{array}$ & Groups & $\begin{array}{c}\text { Percentage of } \\
\text { patients }\end{array}$ \\
\hline Working & 31.7 & Good & 53.5 \\
Housewife & 68.3 & Moderate & 30.7 \\
& & Poor & 15.8 \\
Total & 100 & & 100 \\
\hline
\end{tabular}

Table 4. Education status of the patients

\begin{tabular}{ccc}
\hline Groups & Number of Patients & $\begin{array}{c}\text { Percentage of } \\
\text { patients }\end{array}$ \\
\hline Illiterate & 19 & 18.8 \\
Primary & 2 & 2 \\
Secondary & 50 & 49.5 \\
Higher & 30 & 29.7 \\
Total & 101 & 100 \\
\hline
\end{tabular}

Table 5. Prevalence of Pre-eclampsia and Edema in hyperthyroid patients

\begin{tabular}{cccc}
\hline Groups & $\begin{array}{c}\text { Percentage of } \\
\text { patients }\end{array}$ & Groups & $\begin{array}{c}\text { Percentage of } \\
\text { patients }\end{array}$ \\
\hline Positive & 32.7 & No edema & 28.72 \\
Negative & 67.3 & General & 15.84 \\
& & Peripheral & 17.82 \\
Total & 100 & Pedal & 36.63 \\
& & Abdominal & 0.99 \\
\end{tabular}

\section{Methodology of the Study}

This study was conducted to find the prevalence of preeclampsia and correlation existing among different parameters. The data were collected from hyperthyroidism patients at Center for Nuclear Medicine and Radiotherapy (CENAR), Sandeman Provincial Civil Hospital Quetta and Bolan Medical College, Quetta. The present study was conducted during the period from March 2019 to September 2019.

\section{Questionnaire or Performa}

An appropriate questionnaire was developed to gather the information conferring the scope of study. Evidences about different ethnic groups, medical/gestational history, age and educational status of patients were noted. Besides, thorough physical investigation and clinical parameters were noted.

Study population

One hundred one (101) hyperthyroid female patients of different ethnic groups of Quetta were included in this study. Patients were selected after complete physical examination and investigation.

\section{Inclusion criteria}

1. First inclusion criteria for the study were pregnant hyperthyroid patients. Pre-eclampsia was identified by hypertension with systolic B.P $\geq 140$ and/or diastolic B.P. $\geq 90 \mathrm{~mm}$ of $\mathrm{Hg}$ after 20 weeks of pregnancy, co-existence of one or more of these conditions such as proteinuria (dip sticks $\geq 2+$ or $300 \mathrm{mg}$ or more in a 24-hour urine sample) nonfunctioning of certain maternal organ like kidney and liver, nervous disorders, blood complications, and retarded fetal growth /uterine and placental dysfunction[37]. Hyperthyroidism in patients was identified on the basis of onset of pre-eclampsia and edema [24]. In the OPD of gynecology and obstetrics department, the patients were received with the history of pregnancy $\left(1^{\text {st }}, 2^{\text {nd }}\right.$ and $3^{\text {rd }}$ trimesters) and edema. After examination the signs of doughy edema in the Gynecology department the patients were chosen for additional examinations. After that systolic and diastolic blood pressure was monitored. Women at high risk of developing pre-eclampsia were identified as those who had essential chronic arterial hypertension prior to the pregnancy, insulin-treated diabetes, or an antecedent of severe pre-eclampsia (including eclampsia, HELLP syndrome, and blood pressure $>160 / 110 \mathrm{~mm} \mathrm{Hg}$, imminence of eclampsia, respiratory distress, or renal failure). 2. Women within 15-50 years of age were included in the study and were subdivided in three age groups of 15-25, 26-35 and 3650 years. 
3. Women with menopause age were not considered in the study.

4. Women surgically treated or diagnosed as hypothyroid patients and taking thyroid medications were not included in the study.

5. The un-biasness and purpose of study was described to the participants protecting their privacy.

6. Moreover, patients could refrain from providing the data at any time and no bonding to them to complete the data of research.

7. Then the patients were referred to diagnostic labs for $C B C$, Urine DR and Thyroid profile (T3, T4 and TSH) to confirm preeclampsia. Moreover, levels of Proteinuria in the blood and platelets count were also noted. The data were collected regarding hyperthyroidism and pre-eclampsia according to age, gestational period and obstetric code and laboratory investigations.

8. Blood samples from each study subject were collected to determine the levels of Tri-iodothyronine (T3), TSH (Thyroid Stimulating Hormone), and Tetra-iodothyronine (T4). Similarly, urine samples of each study subject were collected for analysis of proteinuria in the laboratory. The analysis of hyperthyroidism was confirmed by the estimation of T4 and TSH deviation from the normal ranges. The typical references extend for TSH focuses every trimester of pregnancy may be created by every research facility[2].

9. The study subjects (patients) were informed that the researcher would take up the responsibility for the protection of data, for better analysis and fruitful conclusion of the study.

\section{Distribution/formation of patient groups:}

One hundred (101) women were divided in three age groups with sub-division of 4 ethnic background of Pashtoon, Baloch, Panjabi and Others. Here Others ethnic group was comprised of Hazara, Christian and Urdu speaking.

Group I: Women between the age of $15-25$ years.

Group II: Women between the age of 26-35 years.

Group III: Women between the age of 36- 50 years.

Ethnicity: Women of different ethnic groups Pashtoon, Baloch, Punjabi and others were included in the study.

\section{Statistical analysis}

The data was analyzed by descriptive statistics as percentage prevalence of the study.

\section{RESULTS}

This research was piloted from March 2019 to September 2019 on 101 women hyperthyroid patients in association with pre-eclampsia.

\section{Ethnic groups}

Pre-eclampsia has risk factors on the population as well as regional ethnicity.Out of these 101 patients, $61.4 \%$ (62) patients belonged to Pashtoons, 20.8\% (21) were Baloch, and 9.9\% (10) were of Punjabi whereas $7.9 \%$ (8) belonged to other ethnic groups of Balochistan. The maximum number of patients were observed in Pashtoon population.(Table 1).

\section{Age groups}

Pre-eclampsia, is most likely to occur in teenage group as well as after thirty years of age. The results of our study showed that all the patients selected for study were in a reproductive age group of 15-50 years and among these patients, maximum number of patients affected by hyperthyroidism (44 out of 101) were in an age group of 26-35 years and minimum patients were observed in an age group of $15-25$ years. (Table 2 ).

\section{Socioeconomic status}

Socio-economic status play a decisive role in developing preeclampsia in weak women. Women having low economy bear insufficient nutritional status due to that they express extra troubles in getting therapeutic care, initial diagnosis, appropriate screening and treatment. The distributions of working and nonworking women were $31.7 \%$ and $68.3 \%$ respectively (Table 3 ). The results showed that much lower working women were present in the study area than non-working women. Out of these 101 patients, 54 belonged to good socioeconomic status whereas 31 patients had moderate socio-economic status and other 16 patients belonged to poor socioeconomic class (Table $3)$.

\section{Education status}

Education status has a great effect on the onset of hyperthyroidism and pre-eclampsia.Women with low or mid low education are more prone to evolve pre-eclampsia than those with high level of education. Pre-eclampsia condition vary according to age, gravidity and number of pregnancy. It was also noted that out of these 101 of patients, $18.8 \%$ patients were illiterate, $2 \%$ were of primary education level, $(49.5 \%)$ patients had secondary level education and rest of the patients $(29.7 \%)$ had higher education level i.e. under-graduates or graduates (Table 4).

\section{Pre-eclampsia and Edema in hyperthyroid patients}

In our studies, 101 hyperthyroid patients $33(32.7 \%)$ patients were diagnosed with the symptoms of pre-eclampsia. Among 101 hyperthyroid patients, no edema was observed in 29 patients, 37 cases of pedal, 18 peripheral and 16 cases of generalized edema were observed. Only 1 case of abdominal edema was seen (Table 5).

\section{DISCUSSIONS}

The study was conceded from March 2019 to September 2019 on 101 female hyperthyroid patients in association with pre-eclampsia. Hyperthyroidism in United Kingdom occurs in 2/1000 pregnancies. In the United Kingdom $85 \%$ cases of hyperthyroidism in young women are due to Graves' hyperthyroidism .The incidence of hyperthyroidism which is unidentified in women is $4.7 / 1000$ and $0.2 \%$ of women were recently diagnosed and treated in UK[23]. Moreover, incidence of pre-eclampsia in blacks might be identified with a higher prevalence of persistent hypertension[31].

Pre-eclampsia is also effected by the ethnicity. Out of 790 (19.6\%) cases of pre-eclampsia; $49 \%$ were of eclampsia. Risk of death from pre-eclampsia or eclampsia was more for women of 30 or more years and for in African American women [21].

The results of our studies in relation to age and preeclampsia showed that an age group of 15-40 was effected the most. The mean ages of patients were $23.57 \pm 2.99$ years in preeclampsia [7]. A retrospective investigation shows 1,400 matured women of 40 years with 20-29 years women as control group found that pre-eclampsia is increasingly normal among more aged women, paying little respect to equality [5].The results were in agreement with[14][39] in which they observed strong incidence of pre-eclampsia before the age of 40 , with increased chance of hypertension. Moreover, it was found that pre-eclampsia is more common in patients less than 21 but elder than 35 year. The incidence of pre-eclampsia between ages 20 30 years is $40.00 \%$ of patient but after 30 years of age rate of 
development of pre-eclampsia shows positive correlation with progression of age [34],the findings were also in line with the results of our studies. Another study conducted by [26]also revealed severe pre-eclampsia (70\%), in the age group 20-30 years.Our findings were not in agreement with the results of [9], who found occurrence of pre-eclampsia in patients was nearly $8 \%$ in an age group of 25 to 35 years $(72 \%)$ were affected by pre-eclampsia and its complications and minimum patients were observed in an age group of 15-25 years. The difference in findings might be due to the selection of pattern adopted for the collection of data.

Socioeconomic status has a great effect on pre-eclampsia as results showed that less number of working women were present in the study area than non-working women.

Education status has a key role on the occurrence of the disease. The results should that women with low or mid low level education were more inclined to develop pre-eclampsia. The findings were also in harmony with the results of [9] in which they found low level of education and illiteracy $(51.1 \%$ and $39.6 \%$ respectively). The early commencement of disease shared hostile maternal and fetal shocks. Moreover, studies exhibited variations in different ranges of pathophysiological program and late beginning of pre-eclampsia [22][25].

In pre-eclampsia, edema was the most noticeable sign. The results were in line with the results of [32] .The outcomes of the study were also in line with the findings of [14] in which they found edema in $70 \%$ of cases, $9 \%$ of cases was of generalized type of edema according to the findings of [26] who reported $80.8 \%$ of edema. According to [38] statistical differences with $76.7 \%$ higher number of pre-eclampsia cases were also observed. The frequencies of primary and late beginning of preeclampsia were 0.3 and $2.7 \%$ [19]

The symptoms of pre-eclampsia was found in $34.6 \%$ in overall pregnant women the findings were in line with our studies.

\section{CONCLUSION}

It was concluded that hyperthyroidism in association with pre-eclampsia was effected by ethnicity,age,socioeconomic status,education level and the onset of edema.

\section{REFERENCES}

1. Abalos E, Cuesta C, Grosso AL, Chou D, Say L. Global and regional estimates of preeclampsia and eclampsia: a systematic review. European Journal of Obstetrics \& Gynecology and Reproductive Biology. 2013 Sep $1 ; 170(1): 1-7$

2. Alamdari S, Azizi F, Delshad H, Sarvghadi F, Amouzegar A, Mehran L. Management of hyperthyroidism in pregnancy: comparison of recommendations of american thyroid association and endocrine society. Journal of thyroid research. 2013;2013.

3. Ananth CV, Keyes KM, Wapner RJ. Pre-eclampsia rates in the United States, 1980-2010: age-period-cohort analysis. Bmj. 2013 Nov 7;347:f6564.

4. Biondi B, Cooper DS. The clinical significance of subclinical thyroid dysfunction. Endocrine reviews. 2007 Nov 8;29(1):76-131.
5. Bobrowski RA, Bottoms SF. Underappreciated risks of the elderly multipara. American journal of obstetrics and gynecology. 1995 Jun 1;172(6):1764-70.

6. Burman KD, Adler RA, Wartofsky L. Hemiagenesis of the thyroid gland. The American journal of medicine. 1975 Jan $1 ; 58(1): 143-6$.

7. Chaudhary RR, Muddeshwar MG. A STUDY OF THYROID PROFILE AND SERUM ALBUMIN IN PREECLAMPSIA WOMEN. Int J Cur Res Rev| Vol. 2016 Dec;8(23):11.

8. Douglas KA, Redman CW. Eclampsia in the united kingdom. Bmj. 1994 Nov 26;309(6966):1395-400.

9. Farzaneh F, Tavakolikia Z, Soleimanzadeh Mousavi SH. Assessment of occurrence of preeclampsia and some clinical and demographic risk factors in Zahedan city in 2017. Clinical and Experimental Hypertension. 2019 Aug $18 ; 41(6): 583-8$

10. GOLDSMITH RE, STURGIS SH, JACOB L, STANBURY JB. The menstrual pattern in thyroid disease. The Journal of Clinical Endocrinology \& Metabolism. 1952 Jul 1;12(7):84655.

11. Joshi JV, Bhandarkar SD, Chadha M, Balaiah D, Shah R. Menstrual irregularities and lactation failure may precede thyroid dysfunction or goitre. Journal of postgraduate medicine. 1993 Jul 1;39(3):137.

12. Kashanian M, Baradaran HR, Alimohammadi R. RISK FACTORS FOR PRE-ECLAMPSIA, A STUDY IN IRAN: PP. 12.469. Journal of Hypertension. 2010 Jun 1;28:e191.

13. Kashanian M, Baradaran HR, Bahasadri S, Alimohammadi R. Risk factors for pre-eclampsia: a study in Tehran, Iran. Archives of Iranian medicine. 2011 Nov 1;14(6):412.

14. Khaddi S, Choukrallah H, Benmallem K, Benmallem O, Habbal R. Preeclampsia, a particular form of hypertension in pregnant women. Archives of Cardiovascular Diseases Supplements. 2019 Jan 1;11(1):102.

15. Khan KS, Wojdyla D, Say L, Gülmezoglu AM, Van Look PF. WHO analysis of causes of maternal death: a systematic review. The lancet. 2006 Apr 1;367(9516):1066-74.

16. Kuklina EV, Ayala C, Callaghan WM. Hypertensive disorders and severe obstetric morbidity in the United States. Obstetrics \& Gynecology. 2009 Jun 1;113(6):1299306.

17. Lachmeijer AM, Arngrímsson R, Bastiaans EJ, Frigge ML, Pals G, Sigurdardóttir S, Stéfansson H, Pálsson B, Nicolae D, Kong A, Aarnoudse JG. A genome-wide scan for preeclampsia in the Netherlands. European Journal of Human Genetics. 2001 Oct;9(10):758. 
18. Lain KY, Roberts JM. Contemporary concepts of the pathogenesis and management of preeclampsia. Jama. 2002 Jun 26;287(24):3183-6.

19. Lisonkova S, Sabr Y, Mayer C, Young C, Skoll A, Joseph KS. Maternal morbidity associated with early-onset and lateonset preeclampsia. Obstetrics \& Gynecology. 2014 Oct $1 ; 124(4): 771-81$.

20. Livingston, J. C., Sibai, B. M. Chronic hypertension in pregnancy. Obsteteric and Gynecology. 2001; 28: 447-463.

21. MacKay AP, Berg CJ, Atrash HK. Pregnancy-related mortality from preeclampsia and eclampsia. Obstetrics \& Gynecology. 2001 Apr 1;97(4):533-8

22. Madazli R, Yuksel MA, Imamoglu M, Tuten A, Oncul M, Aydin B, Demirayak G. Comparison of clinical and perinatal outcomes in early-and late-onset preeclampsia. Archives of gynecology and Obstetrics. 2014 Jul 1;290(1):53-7.

23. Mandel SJ, Brent GA, LARSEN PR. Review of antithyroid drug use during pregnancy and report of a case of aplasia cutis. Thyroid. 1994;4(1):129-33.

24. Mayer DC, Thorp J, Baucom D, Spielman FJ. Hyperthyroidism and seizures during pregnancy. American journal of perinatology. 1995 May;12(03):192-4.

25. Mifsud W, Sebire NJ. Placental pathology in early-onset and late-onset fetal growth restriction. Fetal diagnosis and therapy. 2014;36(2):117-28.

26. Patnaik US, Devi GR, Anusha K, Suseela AV. Maternal and perinatal outcome in severe pre-eclampsia.

27. RIDGWAY EC, LONGCOPE C, MALOOF F. Metabolic clearance and blood production rates of estradiol in hyperthyroidism. The Journal of Clinical Endocrinology \& Metabolism. 1975 Sep 1;41(3):491-7.

28. Roberts CL, Ford JB, Henderson-Smart DJ, Algert CS, Morris JM. Hypertensive disorders in pregnancy: a population-based study. Medical Journal of Australia. 2005 Apr;182(7):332-5.

29. Roberts JM, Gammill HS. Preeclampsia: recent insights. Hypertension. 2005 Dec 1;46(6):1243-9.

30. Roberts JM, Redman CW. Pre-eclampsia: more than pregnancy-induced hypertension. The Lancet. 1993 Jun 5;341(8858):1447-51.

31. Samadi AR, Mayberry RM, Zaidi AA, Pleasant JC, McGhee Jr N, Rice RJ. Maternal hypertension and associated pregnancy complications among African-American and other women in the United States. Obstetrics \& Gynecology. 1996 Apr 1;87(4):557-63.
32. Santos S, Voerman E, Amiano $P$, Barros $H$, Beilin LJ, Bergström A, Charles MA, Chatzi L, Chevrier C, Chrousos GP, Corpeleijn E. Impact of maternal body mass index and gestational weight gain on pregnancy complications: an individual participant data meta-analysis of European, North American, and Australian cohorts. BJOG: An International Journal of Obstetrics \& Gynaecology. 2019 Jul 1.

33. Say L, Chou D, Gemmill A, Tunçalp Ö, Moller AB, Daniels J, Gülmezoglu AM, Temmerman M, Alkema L. Global causes of maternal death: a WHO systematic analysis. The Lancet Global Health. 2014 Jun 1;2(6):e323-33.

34. Sheraz S, Boota M, Shahzad S. Eclampsia. Professional Medical Journal-Quarterly [The]. 2006:27-31.

35. Steel RG, Torrie JH. Principles and procedures of statistics. Principles and procedures of statistics.. 1960.

36. Tjipto CA, Warsanto JA, Pramono A. Correlation Between Body Mass Index With The Incidence Of Preeclampsia. JOURNAL OF WIDYA MEDIKA JUNIOR. 2019 Mar $4 ; 1(1): 9-12$.

37. Tranquilli AL, Dekker G, Magee L, Roberts J, Sibai BM, Steyn W, Zeeman GG, Brown MA. The classification, diagnosis and management of the hypertensive disorders of pregnancy: a revised statement from the ISSHP. Pregnancy hypertension. $2014 \mathrm{Apr} ; 4(2): 97$

38. Vojvodić L, Sulović V, Pervulov M, Milacić D, Terzić M. The effect of pre-eclampsia on thyroid gland function. Srpski arhiv za celokupno lekarstvo. 1993;121(1-2):4-7.

39. Zibaeenezhad MJ, Ghodsi M, Arab P, Gholzom N. The prevalence of hypertensive disorders of pregnancy in Shiraz, Southern Iran.

40. Zimmermann MB. lodine deficiency. Endocrine reviews. 2009 Jun $1 ; 30(4): 376-408$. 